\title{
MOLECULAR AND BIOCHEMICAL CHARACTERIZATION OF STAPHYLOCOCCUS PSEUDINTERMEDIUS FROM CANINE PYODERMA IN SHIVAMOGGA REGION OF KARNATAKA
}

\author{
Prashantha M K; Shambulingappa B E*; Sundareshan S; \\ Kotresh A M; Rudresh B H; Madhavaprasad C B and Arun S J \\ Veterinary College Shimoga (KVAFSU, Bidar), Karnataka
}

Research Article

Received: 25.02 .2021

Revised: 28.02.2021

Accepted: 06.03.2021

\begin{abstract}
A study on bacteriological investigation of canine pyoderma cases was conducted at the Veterinary College, Shivamogga. Exudate/pus/lesion swabs were collected from clinical cases of canine pyoderma $(n=126)$ and subjected to isolation and identification of bacterial isolates by phenotypic methods. The bacteriological processing of the samples resulted in the recovery of 95 staphylococcal isolates and 18 other bacterial isolates. On culture, staphylococci were the most predominantly ( $\mathrm{n}=95,75.39 \%)$ isolated organisms. The PCR was employed as molecular method in this study for the detection of species of staphylococcal isolates by targeting nuc gene and it was also used for the detection of virulence gene and antibiotic resistance gene in staphylococcal isolates by targeting siet gene and mecA gene, respectively, by using primers published earlier. One of the S. pseudintermedius isolates which confirmed by PCR and sequencing of partial nuc gene was used as positive reference strain for further screening of isolates by PCR.

Based on nuc gene-based PCR, out of 95 staphylococcal isolates obtained, 82 (86.1\%)of the isolates were found belonging to S. pseudintermedius. And out of 82 S. pseudintermedius isolates, siet gene was detected in 69 (86.1\%) isolates. S. pseudintermedius was found to be predominant bacterial pathogen responsible for pyoderma in dogs.
\end{abstract}

Keywords: Canine pyoderma, Staphylococcus pseudintermedius, Nucgene, siet gene, mec A gene, virulence gene.

\section{INTRODUCTION}

Pyoderma is one of the most frequently seen conditions in small animal practice and most of the pyoderma cases in dogs are associated with Staphylococcus species, which are opportunistic pathogen and infection tends to develop secondarily to an underlying cutaneous, metabolic or immunological abnormality (Craig, 2003).Around 90 per cent of pyoderma cases in dogs are associated with bacteria belongs to Staphylococcus species, especially $S$. intermedius is one of the causative agents of canine bacterial skin infections, such as otitis externa, pyoderma and abscesses (Kloos and Bannerman, 1994). Staphylococcus intermedius is an opportunistic bacterial pathogen causing various diseases in dogs. Staphylococcal strains designated up to 2005 as S. intermedius species are currently assembled into the so-called $S$. intermedius group (SIG), consisting of S. intermedius, S. pseudintermedius and S. delphini (Sasaki et al., 2007). It is the $S$. pseudintermedius, and not S.intermedius, is the species of the $S$. intermedius group (SIG) that colonizes and causes infections in dogs and cats (Perreten et al., 2010).The novel species $S$. pseudintermedius is the most significant of the SIG from a clinical point of view. Being an important canine opportunistic pathogen often isolated from dermatitis, otitis and other secondary infections (Sasaki et al., 2007), the SIG particularly S. pseudintermedius, has been implicated as a common cause of pyoderma in dogs (Becker et al., 2005).

*Corresponding author: shambu71@gmail.com 
It is difficult to differentiate $S$. intermedius from $S$. pseudintermedius during routine diagnostic procedures, but the vast majority of canine isolates are S. pseudintermedius. It has therefore been proposed to report all strains belonging to the SIG from dogs as $S$. pseudintermedius; unless genomic investigations prove that the strain belongs to other related species of SIG (Devriese et al., 2009). The most common cause of pyoderma in dogs is the coagulase-positive $S$. pseudintermedius (previously misidentified as Staphylococcus intermedius) (Jones et al., 2007). Staphylococcus pseudintermedius is one of the most common pathogens isolated from skin and postoperative infections in dogs and cats (Stegmann et al., 2010).Hence the present study was undertaken with an objective to isolate Staphylococcus species from canine pyoderma in Shivamogga region of Karnataka and an attempt was made to identify the Staphylococcus pseudintermedius by molecular methods.

\section{MATERIALAND METHOD}

The study was conducted in the Department of Veterinary Microbiology, Veterinary College, Shivamogga, a constituent institute under Karnataka Veterinary, Animal and Fisheries Sciences University, Bidar, Karnataka State.

\section{Isolation of bacterial agents from samples collected from canine pyoderma cases:}

\section{a. Collection of clinical samples and the data pertaining to the cases:}

Clinical cases of canine pyoderma presented to teaching veterinary clinical complex Shivamogga were used for collecting samples in this study. The veterinarians who were practicing in the study area (in and around Shivamogga) who volunteered to send from their respective district polyclinic veterinary dispensaries/Veterinary hospitals were also used in the study. All the cases of pyoderma such as papules, pustules, erythema, alopecia, pruritus and epidermal collarettes were selected as subjects for bacterial culture and antimicrobial sensitivity assay. The detailed information of the cases with regard to the breed, age, sex of the dogs including the lesions observed and the underlying causes were recorded for further analysis.

\section{b. Culturing of samples for Isolation of bacteria}

The clinical material collected using sterile swabs from the lesions was initially inoculated in BHI broth and incubated for $12-24$ hrs at $37^{\circ} \mathrm{C}$, Primary identification of bacterial agents were carried out based on colony morphology, and Gram's staining. A loopful of the inoculum was then streaked on to pre-prepared mannitol salt agar and MacConkey agar petriplates and incubated for $24 \mathrm{hrs}$ at $37^{\circ} \mathrm{C}$ and examined as per the standard procedure described by Cruickshank et al. (1975).

\section{Identification of bacterial agents by phenotypic methods}

\section{Grams staining and cultural characters}

Gram's staining kit, which contained Crystal violet, Gram's iodine, Decolorizer and Safranin was procured from M/s Hi-Media, Mumbai. Staining of all the culture isolates was carried out as per the instructions mentioned in the kit and differentiated as gram positive and gram negative and documented.

On the agar plates colony morphology and lactose fermenter/non fermenters were recorded. Grams staining of the pure colonies so obtained on the plates were carried out and the primary identification of bacterial isolates were done based on colony morphology. Then the selective plating of the isolates was carried out for further confirmation. Then relevant biochemical tests were carried out for gram positive and gram-negative isolates so obtained as per the standard procedure (Collee et al., 1989) as follows.

\section{Biochemical tests}

The recovered isolates confirmed by Gram's staining were further subjected to biochemical tests such as coagulase and catalase tests to confirm coagulase positive staphylococci and the aerobic bacterial isolates and other isolates were confirmed by conventional biochemical tests like oxidase and IMVIC tests.

\section{Coagulase test}

All the staphylococcal isolates confirmed preliminarily by Grams staining were first subjected totube coagulase test. For this, about $0.3 \mathrm{ml}$ of $18 \mathrm{hr}$ old Staphylococcus culture in BHI broth was mixed with $0.5 \mathrm{ml}$ of diluted rabbit plasma (1:4 in PBS) and incubated overnight at $37^{\circ} \mathrm{C}$. The result was recorded at $1 \mathrm{hr}, 4 \mathrm{hr}$ and after overnight incubation. Formation of clot/ stiff gel which remained in place when tube was tilted through $90^{\circ}$ angle or inverted was considered as positive for coagulase production. The tubes were read negative when plasma remained liquid or showed only 
a flocculent or ropy precipitate even after overnight incubation and only such isolates negative by coagulase test were further subjected to various biochemical tests as follows (Collee et al., 1989).

\section{Catalase test}

Ebullition of gas bubbles after the addition of $24 \mathrm{hr}$ culture to 3\% hydrogen peroxide indicated the positive reaction. Absence of ebullition of gas bubbles indicated the negative reaction and only catalase positive cultures were considered for further characterization.

\section{Identification of staphylococcal isolates by molecular methods:}

\section{a. DNA extraction}

The DNA was extracted as per the procedure described by Arakere et al. (2005).

Materials: Uniflex ${ }^{\mathrm{TM}}$ DNA isolation kit (Genei, Bangalore), Spectrophotometer, Sterile DNase free Micropipette tips and Microcentrifuge tubes (Genei), Micropipettes (Eppendorf, Germany), Ethanol (96$100 \%)$

Procedure: Cells from an overnight culture in BHI broth collected by centrifugation (600 $0 \mathrm{rpm}$ for 10 minutes) were suspended in lysis buffer (phosphate buffered saline containing $0.5 \%$ sodium dodecyl sulphate and $100 \mu \mathrm{g} / \mathrm{ml}$ proteinase $\mathrm{K}$ ). The cell suspension was incubated at $37^{\circ} \mathrm{C}$ for 1 hour, and an equal volume of phenol: chloroform (1:1) mixture was added to the cell suspension and vortexed. The samples were centrifuged at 12,000 rpm for 20 minutes and the aqueous phase was transferred to a fresh tube. The DNA was precipitated by centrifugation (12,000 rpm, 20minutes) at room temperature after adding 0.1 suspension volume of $3 \mathrm{M}$ sodium acetate ( $\mathrm{pH}$ 5.2) and 2.0-3.0 suspension volumes (calculated after the addition of salt) of $99 \%$ cold ethanol. The DNA pellet was washed twice with cold $70 \%$ alcohol, air dried, and suspended in $500 \mu \mathrm{L}$ of TE buffer (10 Mm Tris- $\mathrm{HCl}$ (pH 8.0), $1 \mathrm{mM}$ EDTA [pH 8]). The concentration of the purified DNA was determined using Nano Drop 2000c (Thermo Fischer Scientific Inc, Waltham, MA, USA). The ratio of 260/280 OD was calculated. A ratio of 1.7 to 1.9 was considered pure. Further, the purity of DNA sample was checked by electrophoresis on 2.0 per cent agarose gel and the DNA was stored at $-20^{\circ} \mathrm{C}$ until further use.

\section{b. Determination of purity and yield of the DNA samples}

The purity and concentration of the extracted genomic DNA was estimated by UV spectrophotometry. An aliquot of $20 \mu \mathrm{L}$ of DNA sample was dissolved in 0.98 $\mathrm{ml}$ of sterile DW. The diluted DNA was transferred into $1 \mathrm{ml}$ microcuvette and the optical density (OD) was read at 260nm and 280nm in a UV spectrophotometer. Sterile DW was used as blank (Boesenberget al., 2012).

The ratio of 260/280 OD was calculated. A ratio of 1.7 to 1.9 was considered as pure. Further, the purity of the DNA sample was checked by electrophoresis on 0.8 per cent agarose gel.

\section{c. Agarose gel electrophoresis for confirmation of DNA}

DNA was confirmed by agarose gel electrophoresis and was carried out as per Lee et al. (2012). The $0.5 \mu \mathrm{g}$ DNA was used to check the purity by electrophoresis on 0.8 $\%$ agarose gel.

\section{d. Preparation of the gel}

Agarose (0.8\%) was prepared in Erlenmeyer flask by adding $0.8 \mathrm{~g}$ of agarose to $100 \mathrm{ml}$ of running buffer (TAE buffer: $40 \mathrm{mM}$ Tris-acetate, $1 \mathrm{mM}$ EDTA) as per Viljoen et al., 1993.

\section{e. Setting up of gel apparatus and separation of DNAfragments}

Loading dye was added to the DNA samples to be separated. DNA size marker was loaded along with samples. Lid was replaced into the gel box. The gel was placed in such a way that cathode (black leads) was closer the wells than the anode (red leads). Gel running was carried out until the dye has migrated to an appropriate distance (Lee et al., 2012).

\section{f. Observing separated DNA fragments}

When electrophoresis has completed, power supply was turned off and lid of the gel box was removed. Gel removed from the gel box. Excess buffer from the surface of the gel was drained off. Gel tray was placed on paper towels to absorb any extra running buffer. Gel was removed from the gel tray and exposed to UV light. DNA bands which were shown up as orange fluorescent bands were documented. Simultaneously the gel was observed and the photos were taken in the gel documentation unit and the gel was properly disposed.

Molecular detection of Staphylococcus pseudintermedius (nuc gene) by PCR

Procedure

The PCR was carried out targeting nuc gene as per the 
procedure described by Chitra et al. (2015). The PCR was carried out using published primers of Chitra et al.

(2015) as shown in table 1.

Table 1: Oligonucleotide sequences of $S$. pseudintermediusnuc gene primers.

\begin{tabular}{|l|c|c|}
\hline $\begin{array}{l}\text { Name of the primer } \\
\text { Staph nuc-F }\end{array}$ & $\begin{array}{c}\text { Primer sequence 5'-3' } \\
\text { AAACACCGAGTAATACGCCG }\end{array}$ & Product size (bp) \\
\cline { 1 - 2 } Staph nuc-R & TTTAGCGTTCCCAAATGTTCAG & \\
\hline
\end{tabular}

The reaction mixture of $25 \mu \mathrm{l}$ each was prepared in $0.2 \mathrm{ml}$ thin-walled PCR tubes placed in mini cooler as shown below (Table 2).

Table 2: Details of the contents of PCR mixture for nuc gene-based PCR.

\begin{tabular}{|l|l|}
\hline Reagents (Concentration) & Volume \\
\hline Master mix (Ampliqon Taq DNA Polymerase Master Mix RED,2x) & $12.5 \mu \mathrm{L}$ \\
\hline Staph nuc-F $(12.5 \mu \mathrm{L} / \mathrm{ml})$ & $1 \mu \mathrm{L}$ \\
\hline Staph $n$ nuc-R $(12.5 \mu \mathrm{L} / \mathrm{ml})$ & $1 \mu \mathrm{L}$ \\
\hline Template (Staphylococcal DNA) & $3 \mu \mathrm{L}$ \\
\hline Nuclease Free Water & $7.5 \mu \mathrm{L}$ \\
\hline TOTAL & $\mathbf{2 5} \boldsymbol{\mu L}$ \\
\hline
\end{tabular}

After mixing the contents, tubes were centrifuged to collect the contents in the bottom. The amplifications were performed in a thermal cycler (Biorad T 300) and the thermal conditions were set as detailed as per Chitra et al., 2015.

After completion of PCR reaction, $3 \mu \mathrm{l}$ of the amplified product was loaded onto a pre prepared 1.5-2 per cent agarose gel (prepared in $1 \mathrm{x}$ TAE buffer) containing ethidium bromide at the concentration of $1 \mu \mathrm{l} / 10 \mathrm{ml}$. marker (DNA ladder), positive control, negative control and no template control was also loaded onto one well each, and gel was made to run in a gel electrophoresis unit using a $1 x$ TAE buffer. Later gel was read under gel documentation unit and the images were captured using gel documentation system; Gel Doc XR (Bio-Rad., U.S.A).

\section{Reference strain}

Two of the PCR positive samples which were commercially sequenced (Eurofins Genomics India Pvt Ltd.,) and the sequencing results obtained were edited using Mega version software and then compared with sequences deposietd in NCBI. These samples which showed $100 \%$ similarity with the corresponding partial gene sequence of nuc of $S$. pseudintermedius were used as positive reference strains in the study.

Detection of virulence gene (siet gene) using PCR Procedure: The isolates were subjected to PCR for detection of siet gene responsible for its virulence. The PCR was carried out using published primers and the procedure described by Ananda Chitra et al. (2018) as shown in below table 3 . The reaction mixture of $25 \mu l$ each was prepared in $0.2 \mathrm{ml}$ thin-walled PCR tubes placed in mini cooler as shown below (Table 4).

Table 3: Oligonucleotide sequences of $S$. pseudintermedius siet gene primers.

\begin{tabular}{|l|c|c|}
\hline Name of the primer & Primer sequence 5'-3' & Product size (bp) \\
\hline Staph siet $-\mathrm{F}$ & TGCGGGTCCTCA ATCTTTAAC & 465 \\
Staph siet $-\mathrm{R}$ & CTTTCAACTCTGCACGCAATC & \\
\hline
\end{tabular}


Table 4: Details of the contents of PCR mixture for siet gene-based PCR.

\begin{tabular}{|l|l|}
\hline Reagents (Concentration) & Volume \\
\hline Master mix (Ampliqon Taq DNA Polymerase Master Mix RED,2x) & $12.5 \mu \mathrm{L}$ \\
\hline Staph siet-F $(12.5 \mu \mathrm{L} / \mathrm{ml})$ & $1 \mu \mathrm{L}$ \\
\hline Staph siet-R $(12.5 \mu \mathrm{L} / \mathrm{ml})$ & $1 \mu \mathrm{L}$ \\
\hline Template (Staphylococcal DNA) & $3 \mu \mathrm{L}$ \\
\hline Nuclease Free Water & $7.5 \mu \mathrm{L}$ \\
\hline TOTAL & $\mathbf{2 5} \boldsymbol{\mu L}$ \\
\hline
\end{tabular}

After mixing the contents, tubes were centrifuged to collect the contents in the bottom. The amplifications were performed in a thermal cycler (Biorad T 300) and the thermal conditions were set as per AnandaChitraet al., 2018.

After completion of PCR reaction, $3 \mu \mathrm{l}$ of the amplified product was loaded onto a pre prepared 1.5 -2 per cent agarose gel (prepared in $1 \mathrm{x}$ TAE buffer) containing ethidium bromide at the concentration of $1 \mu \mathrm{l} / 10 \mathrm{ml}$. marker (DNA ladder), positive control, negative control and no template control was also loaded onto one well each, and gel was made to run in a gel electrophoresis unit using a 1x TAE buffer. Later gel was read under gel documentation unit and the images were captured using gel documentation system; Gel Doc XR(Bio-Rad., U.S.A).

\section{Detection of mecAgene by PCR}

\section{Procedure}

The PCR was carried out using published primers of Chitra et al. (2015) as shown in below (Table 5). The reaction mixture of $25 \mu \mathrm{l}$ each was prepared in $0.2 \mathrm{ml}$ thin walled PCR tubes placed in mini cooler as shown below (Table 6).

Table 5: Oligonucleotide sequences of $S$. pseudintermedius mecAgene primers.

\begin{tabular}{|l|c|c|}
\hline Name of the primer & Primer sequence 5'-3' & Product size (bp) \\
\hline Staph mec A -FC & AAACTACGGTAACATTGATCGC & 210 \\
\hline Staph mec A - R & GCCTATCTCATATGCTGTTCCT & \\
\hline
\end{tabular}

Table 6: Details of the contents of PCR mixture for mecAgene-based PCR.

\begin{tabular}{|l|l|}
\hline Reagents (Concentration) & Volume \\
\hline Master mix (Ampliqon Taq DNA Polymerase Master Mix RED,2x) & $12.5 \mu \mathrm{L}$ \\
\hline Staph mec A -F (12.5 $\mu \mathrm{L} / \mathrm{ml})$ & $1 \mu \mathrm{L}$ \\
\hline Staph mec A -R $(12.5 \mu \mathrm{L} / \mathrm{ml})$ & $1 \mu \mathrm{L}$ \\
\hline Template (Staphylococcal DNA) & $3 \mu \mathrm{L}$ \\
\hline Nuclease Free Water & $7.5 \mu \mathrm{L}$ \\
\hline TOTAL & $\mathbf{2 5} \boldsymbol{\mu L}$ \\
\hline
\end{tabular}


After mixing the contents, tubes were centrifuged to collect the contents in the bottom. The amplifications were performed in a thermal cycler (Biorad T 300) and the thermal conditions were set as per Chitra et al., 2015.

After completion of PCR reaction, $3 \mu$ l of the amplified product was loaded onto a pre prepared 1.5-2 per cent agarose gel (prepared in $1 \mathrm{x}$ TAE buffer) containing ethidium bromide at the concentration of $1 \mu \mathrm{l} / 10 \mathrm{ml}$. marker (DNA ladder), positive control, negative control and no template control was also loaded onto one well each, and gel was made to run in a gel electrophoresis unit using a $1 \mathrm{x}$ TAE buffer. Later gel was read under gel documentation unit and the images were captured using gel documentation system; Gel Doc XR (Bio-Rad., U.S.A).

\section{RESULTS AND DISCUSSION}

In the present study, staphylococci were confirmed by biochemical tests and all the staphylococcal isolates were catalase and coagulase positive. In this study the total number of staphylococcal isolates obtained was 95 (75.5\%) out of 126 samples collected and processed.

\section{Identification of S. pseudintermedius by molecular method \\ Ninety-five staphylococcal isolates confirmed phenotypically were further subjected for the PCR targeting nuc gene for the identification of $S$. pseudintermedius.}

PCR was carried out for the 95 staphylococcal isolates targeting nис gene. Of these 82 isolates yielded 780bp amplicon specific for $S$. pseudintermedius (Plate6).Two PCR products of representative samples (sample 6 and 10) were sent for the commercial sequencing (Eurofins Genomics India Pvt Ltd). The chromatogram and the nucleotide sequence obtained by sequencing were analyzed and edited using Mega version software. Further the edited nucleotide sequences were compared with deposited sequences of NCBI using BLAST tool and the sequence showed $100 \%$ sequence similarity with corresponding nuс gene sequence partial of S. pseudintermedius (Table 7, Fig.1).

The results are supported by the work done by Bannoehr and Guardabassi (2012) who reported that $S$. pseudintermedius was the most prevalent coagulase- positive staphylococci inhabitant of the skin and mucosa of dogs and cats. It was also the major bacterial pathogen isolated from canine infections. Similar work done by Ruzauskas et al. (2016) reported in a study that 192 samples (76.8\%) of the 250 samples collected from dogs tested positive for Staphylococcus species. The percentage was higher in non-treated animals (89.5\%).

\section{Detection of thermonuclease (nuc) gene}

It is difficult to differentiate $S$. intermedius from $S$. pseudintermedius during routine diagnostic procedures, but the vast majority of canine isolates are S. pseudintermedius. It has therefore been proposed to report all strains belonging to the SIG from dogs as $S$. pseudintermedius; unless genomic investigations prove that the strain belongs to a related species (Devriese et al., 2009). Conventional microbiological diagnostic tests often fail to distinguish between $S$. pseudintermedius and $S$. intermedius, such that $S$. pseudintermedius were frequently misidentified as $S$. intermedius or S. aureus (Sasaki et al.,2007 and Van Hoovels et al., 2006)

In a study by Sasaki et al. (2007), detection of the nuc gene, encoding thermonuclease, was carried out for SIG strains by PCR and PCR products were sequenced directly.

Chitra et al. (2015) in a study reported that PCR targeting nuс gene was a useful tool in preliminary identification of S. pseudintermedius and was also used to differentiate S. pseudintermedius isolates from other coagulase positive staphylococcal species such as S. aureus and Staphylococcus intermedius organisms.

In this present study, a total of 95 staphylococcal isolates were subjected for species detection by nucgene-based PCR, of which, 82 (86.3\%) isolates gave positive results yielding amplified products of 780bp.

The results are supported by a study of Becker et al, (2005) that except for the limitations with isolates of hoofed animals, the S. intermedius nuc PCR assay has potential for rapid identification of $S$. intermedius and differentiation from other CoPS including S. aureus and the nuc gene was amplified in $94.9 \%$ of staphylococcal isolates. 
Bannoehret al. (2007) reported that the lack of unique phenotypic markers for $S$. pseudintermedius in comparison to the other SIG members has precluded its identification without DNA sequencing. Importantly, due to the presence of common phenotypic markers, $S$. pseudintermedius is occasionally misidentified as $S$. aureus in human clinical diagnostic laboratories (Pottumarthy et al., 2004).

Ananda Chitra et al. (2018) developed species specific PCR and screened 91 samples collected between February 2013 and February 2014 from various skin infections of dogs of different breeds, age and sex. $S$. pseudintermedius was isolated from 53 (59 \%) animals.
A higher rate of isolation of $S$. pseudintermedius have been reported in pyoderma cases from Japan (76 \%) by Onuma et al. (2012), Germany (76\%) by Ruscher et al. (2009) and South Korea (61 \%) by Yoon et al. (2010). Lesser rate of isolation like $52 \%$ from both diseased and healthy dogs was noticed in Poland by Garbacz et al. (2013) and 55 per cent from healthy dogs in Tunisia by Elhani et al. (2015). However, a very lower isolation rate was observed with 16 per cent from healthy and diseased dogs in south China by Feng et al. (2012) and 26.5 per cent from pyoderma cases in North China by Wang et al. (2012).

Table 7: PCR based detection of nuc, siet,and mecA genes in staphylococcal isolates.

\begin{tabular}{|l|l|l|c|}
\hline SI. No. & $\begin{array}{l}\text { No. of isolates } \\
\text { subjected for PCR }\end{array}$ & Gene targeted & No. of isolates positive by PCR (percentage) \\
\hline 1 & 95 & nuc gene & $82(86.31 \%)$ \\
\hline 2 & 82 & siet gene & $69(84.14 \%)$ \\
\hline 3 & 82 & mecAgene & $03(3.65 \%)$ \\
\hline
\end{tabular}

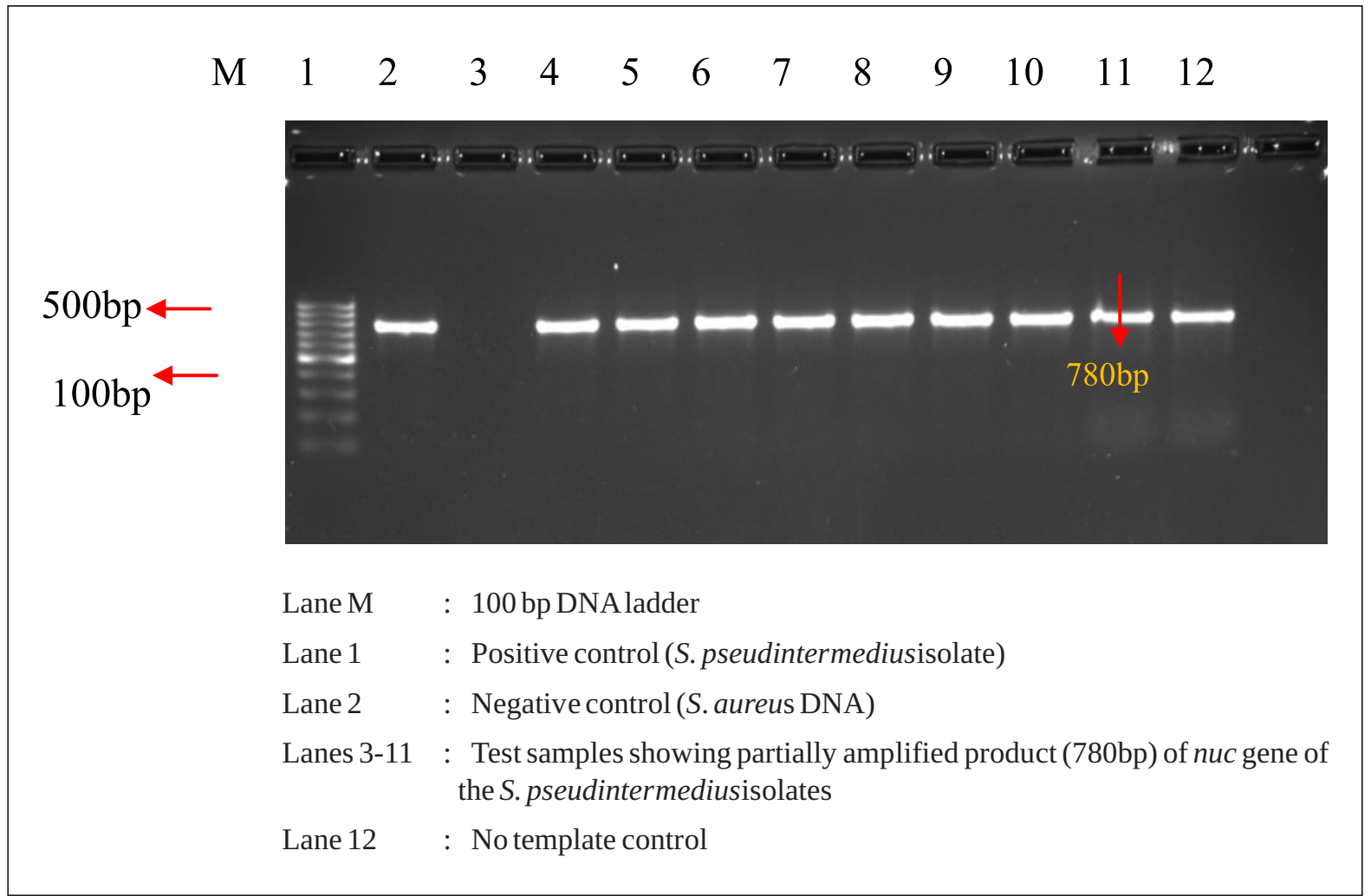

Plate 6: Partial amplification of nuc gene of $S$. pseudintermedius by PCR. 


\section{SUMMARY}

Nucgene-based PCR detection can be used a reliable diagnostic tool for laboratory diagnosis of $S$. pseudintermedius infections and in this study, it detected $86.3 \%$ of the staphylococcal isolates as $S$. pseudintermedius.

Siet gene encoding exfoliative toxin an important virulence factor associated with skin affections was detected in 72.6 per cent of the $S$. pseudintermedius isolates.

\section{REFERRENCE}

1. Ananda Chitra, M., Jayanthy, C. and Nagarajan, B., 2018. Virulence genes detection and antimicrobial susceptibility of Staphylococcus pseudintermedius Isolates from canine skin infection in Chennai, India. Proceedings of the National Academy of Sciences, India Section B: Proc. Biol. Sci..,88(1): 355-361

2. Bannoehr, J. and Guardabassi, L., 2012. Staphylococcus pseudintermedius in the dog: Taxonomy, diagnostics, ecology, epidemiology and pathogenicity. Vet. Dermatol., 23(4): 253.

3. Bannoehr, J., Zakour, N.L.B., Waller, A.S., Guardabassi, L., Thoday, K.L., Van Den Broek, A.H. and Fitzgerald, J.R., 2007. Population genetic structure of the Staphylococcus intermedius group: Insights into agr diversification and the emergence of methicillin-resistant strains. やJ. Bacteriol., 189 (23): 8685-8692.

4. Becker, K., Von Eiff, C., Keller, B., Bruck, M., Etienne, J. and Peters, G., 2005. Thermonuclease gene as a target for specific identification of Staphylococcus intermedius isolates: use of a PCR-DNA enzyme immunoassay. Diagn. Microbiol. Infect. Dis.,51 (4):237-244.

5. Chaitra, M.A., Jayanthy, C. and Nagarajan, B., 2015. Detection and sequence analysis of accessory gene regulator genes of Staphylococcus pseudintermedius isolates. Vet World., 8(7):902.

6. Collee, J.G., Miles, R.S. and Watt, B., 1989. Tests for identification of bacteria Mackie and McCartney Practical Medical Microbiology. JG Collee, JP Duguid, AG Fraser and BP Marmion (eds.), 2:141-159.
7. Craig, M., 2003. Diagnosis and management of pyoderma in the dog. In practice, 25(7):418-425.

8. Cruickshank., Robert., 1975 Medical microbiology: The practice of medical microbiology. Vol. 2. Churchill Livingstone, pp:236-278.

9. Devriese, L.A., Hermans, K., Baele, M. and Haesebrouck, F., 2009. Staphylococcus pseudintermediusversus Staphylococcusintermedius Vet. Microbiol., 1 (133):206-207.

10. Devriese, Luc A., Katleen Hermans, Margo Baele, and Freddy Haesebrouck. 2009 "Staphylococcus pseudintermedius versus Staphylococcus intermedius." Vet. Microbiol., 1(133): 206-207.

11. Elhani, D., Gharsa, H., Kalai, D., Lozano, C., Gómez, P., Boutheina, J., Aouni, M., Barguellil, F., Torres, C. and Slama, K.B., 2015. Clonal lineages detected amongst tetracycline-resistant meticillin-resistant Staphylococcus aureus isolates of a Tunisian hospital, with detection of lineage ST398. J. Med. Microbiol.,64(6):623629.

12. Feng, Y., Tian, W., Lin, D., Luo, Q., Zhou, Y., Yang, T., Deng, Y., Liu, Y.H. and Liu, J.H., 2012. Prevalence and characterization of methicillin-resistant Staphylococcus pseudintermedius in pets from South China. Vet.Microbiol., 160(3-4):517-524.

13. Garbacz, K., Żarnowska, S., Piechowicz, L. and Haras, K., 2013. Pathogenicity potential of Staphylococcus pseudintermedius strains isolated from canine carriers and from dogs with infection signs. Virulence, 4(3):255-259.

14. Jones, R.D., Kania, S.A., Rohrbach, B.W., Frank, L.A. and Bemis, D.A., 2007. Prevalence of oxacillin-and multidrug-resistant staphylococci in clinical samples from dogs: 1,772 samples (2001-2005). J Am Vet Med A, 230(2):221-227.

15. Kloos, W.E. and Bannerman, T.L., 1994. Update on clinical significance of coagulasenegative staphylococci. Clin Microbiol Rev, 7(1):117-140.

16. Lee, P.Y., Costumbrado, J., Hsu, C.Y. and Kim, Y.H., 2012. Agarose gel electrophoresis for the separation of DNA fragments. J.o.Ve, 62:e3923. 
17. Onuma, K., Tanabe, T. and Sato, H., 2012. Antimicrobial resistance of Staphylococcus pseudintermedius isolates from healthy dogs and dogs affected with pyoderma in Japan. Vet dermatol., 23(1):17-e5.

18. Perreten, V., Kadlec, K., Schwarz, S., Gronlund Andersson, U., Finn, M., Greko, C., Moodley, A., Kania, S.A., Frank, L.A., Bemis, D.A. and Franco, A., 2010. Clonal spread of methicillin-resistant Staphylococcus pseudintermedius in Europe and North America: an international multicentre study. J. Antimicrob. Chemother, 65(6):1145-1154.

19. Pottumarthy, S., Schapiro, J.M., Prentice, J.L., Houze, Y.B., Swanzy, S.R., Fang, F.C. and Cookson, B.T., 2004. Clinical isolates of Staphylococcusintermedius masquerading as methicillin-resistant Staphylococcus aureus. 円. Clin. Microbiol, 42(12):5881-5884.

20. Ruscher, C., Lübke-Becker, A., Wleklinski, C.G., Şoba, A., Wieler, L.H. and Walther, B., 2009. Prevalence of methicillin-resistant Staphylococcus pseudintermedius isolated from clinical samples of companion animals and equidaes. Vet microbiol, 136(1-2):197-201.

21. Ruzauskas, M., Couto, N., Kerziene, S., Siugzdiniene, R., Klimiene, I., Virgailis, M. and Pomba, C., 2015. Prevalence, species distribution and antimicrobial resistance patterns of methicillin-resistant staphylococci in Lithuanian pet animals. Acta Veterinaria Scandinavica, 57(1):27.

22. Sasaki, T., Kikuchi, K., Tanaka, Y., Takahashi, N., Kamata, S. and Hiramatsu, K., 2007.
Reclassification of phenotypically identified Staphylococcusintermedius strains. やJ. Clin. Microbiol, 45(9):2770-2778.

23. Stegmann, R., Burnens, A., Maranta, C.A. and Perreten, V., 2010. Human infection associated with methicillin-resistant Staphylococcus pseudintermedius ST71. J. Antimicrob. Chemother, 65(9):2047-2048.

24. Van Duijkeren, E., Catry, B., Greko, C., Moreno, M. A., Pomba, M. C., Pyorala, S., Ruzauskas, M., Sanders, P., Threlfall, E. J., Torren- Edo, J and Torneke, K. 2011. Review on methicillin-resistant Staphylococcus pseudintermedius. J. Antimicrob. Chemother., 66: 2705-2714.

25. Viljoen, C.D., WINGFIELD, B.D. and WINGFIELD, M.J., 1993. Agar, an alternative to agarose in analytical gel electrophoresis. Biotechnology techniques, 7(10):723-726.

26. Wang, Y., Yang, J., Logue, C.M., Liu, K., Cao, X., Zhang, W., Shen, J. and Wu, C., 2012. Methicillin-resistant Staphylococcus pseudintermedius isolated from canine pyoderma in North China. J. Appl. Microbiol., 112(4):623630 .

27. Yoon, J.W., Lee, K.J., Lee, S.Y., Chae, M.J., Park, J.K., Yoo, J.H. and Park, H.M., 2010. Antibiotic resistance profiles of Staphylococcus pseudintermedius isolates from canine patients in Korea. J Microbiol Biotechnol, 20(12):17641768. 